\title{
Circular Economy Applied to Organic Residues and Wastewater: Research Challenges
}

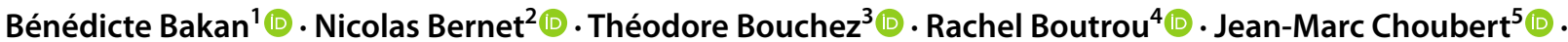

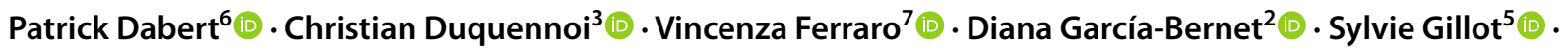

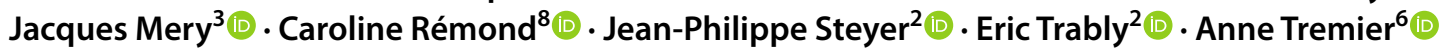

Received: 20 May 2021 / Accepted: 15 August 2021 / Published online: 24 August 2021

(c) The Author(s) 2021

\begin{abstract}
To move today's agricultural and urban systems towards tomorrow's circular economy and respond to climate change, it is imperative to turn organic residues and wastewater into resourceful assets. This article discusses the changes that are needed in research to drive this paradigm shift and to go from a "losses and waste" situation to a "resource and opportunities" ambition. The current lines of research aim to maximise the use and value of biomass or organic residues and wastewater and propose new organisational schemes driven by technical innovations. Exploring the pathways to a sustainable future through many domains let us identify five challenges to structure the research efforts and find circular bioeconomy solutions for organic residues and wastewater: (1) proposing innovative processes and integrated multi-process systems; (2) promoting the emergence of multi-scale and cross-sectoral organisations; (3) developing multi-performance evaluation methods, (4) rethinking research-society intersections, and (5) enhancing research-legislation interactions. We end by outlining prospects for moving forward past current limitations: beyond increasing knowledge, research will continue its own transition. Our responsibility today is not to think about what we could do for a better world but what we should do to make our ever-changing world even better and more sustainable.
\end{abstract}

\section{Graphic Abstract}

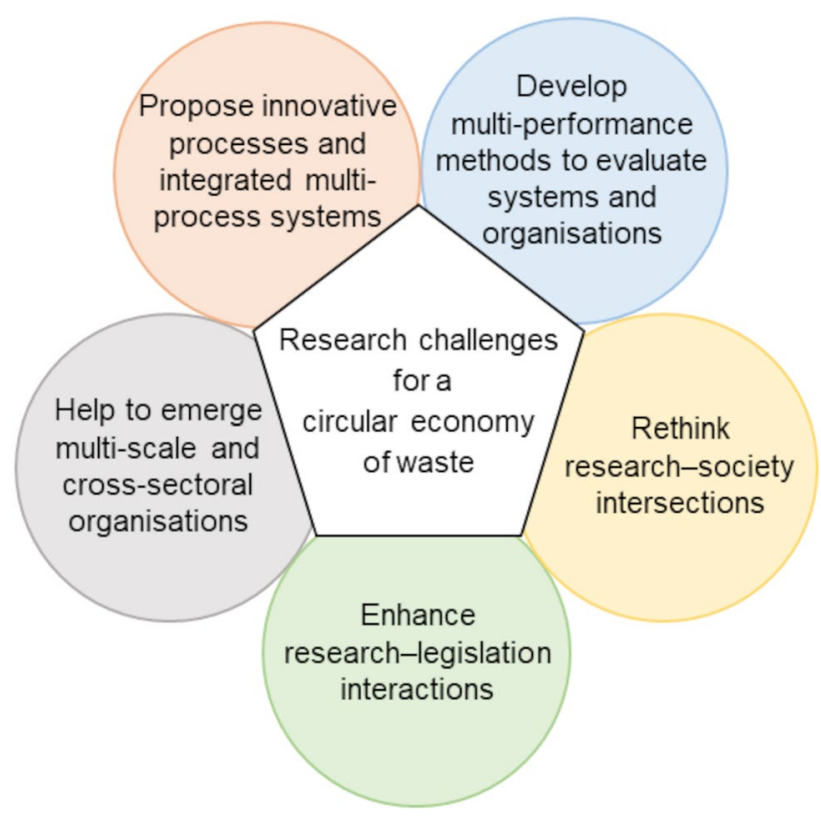

Extended author information available on the last page of the article 
Keywords Biotechnology $\cdot$ Circular bioeconomy $\cdot$ By-product valorisation · Impact of science $\cdot$ Sustainability $\cdot$ Waste management

\section{Statement of Novelty}

This article is a position paper from researchers involved in engineering related to bioeconomy and having a long-term expertise in the coordination of collaborative projects. As such, its main interest is to gather all-important multidisciplinary aspects. The manuscript provides a framework by identifying five challenges for future research. The novelty is to assemble them in one location in a coherent framework in which researchers and engineers can think about their research and fully realize what they are in charge in. Even if some ideas may sound familiar, in each of the five sections, the challenges are briefly illustrated by examples from diverse biomass and waste valorisation that could inspire anyone involved in this field.

\section{Introduction}

For the past century, society has grown along a linear paradigm of extracting resources on one side of the planet to transform, exploit and most often dump residues in other places of the world, resulting in a total disconnection within natural organic and inorganic matter cycles. This is the case of the extraction of petroleum, coal, phosphorus, rare earths, raw materials used in animal feed, and even for the production of materials such as plastics. Modern value chains are often split into separate areas in the world between extraction, production, consumption and waste, which does not facilitate life-cycle approaches and circular bioeconomies. Furthermore, this globalised pattern of intensive resource use charts a trajectory to near-total depletion [1-3] with 'collateral' damage and impacts. They include climate change, water, air and soil pollution, loss of biodiversity and, ultimately, threaten the continued health and geopolitical stability of the planet.

According to the latest FAO (Food and Agricultural Organization of UN) estimates [4], roughly a third of all food produced ends up as residues (by-products and waste), which amounts to about 1.3 billion tons worldwide each year. It results from edible food lost during food production and postharvest handling and from discarded foodstuff such as unsold food, food preparation leftovers and uneaten food from households, restaurants and large producers, as collective caterers and supermarkets [5]. At the same time, according to the World Bank figures for 2016, the world's cities generate 2.01 billion tons of waste per year, with 3.40 billion tons expected in 2050, half of which being organic waste $[6,7]$. All this organic waste induces health-hygiene problems and nuisances that put strong environmental, economic and social pressure on urban centres. However, it is also an underexploited resource that, if better managed, could be used to produce materials, added-value products, soil amendments and energy, to support the development of a more sustainable societal model [8-10], as illustrated for agriculture by-products on Fig. 1. In this regard, scientists (illustrated by a magnifying glass on Fig. 1) lead research to enable (i) a cascade-valorization of food-industry by-products into resource added-value molecules while (ii) minimizing the waste. The development of such research parallels the increasing in the knowledge of the composition of raw materials for theirs optimal valorization, easing bottlenecks for ad-hoc extraction/treatment processes to recover valuable molecules and determining applications for their functionalities in target fields (Fig. 1).

The United Nations, through its 2030 sustainable development goals report [11], states the necessity "to accelerate responses to the world's gravest challenges-from eliminating poverty and hunger to reversing climate change". This global objective opens wide perspectives for innovation but requires a rethink of usual scientific approaches to adopt a more systemic vision of all sectors of society. Actually, the core idea for initiating innovations can have multiple origins. Innovations can be incremental, by optimising a transformation chain step-by-step, or can stem from scientific discoveries generating new technologies that must then find their way to the market. New regulations, societal demand or economic constraints can also trigger new technology developments or innovative process chain structuration. In the field of organic residues and wastewater management, the role of scientists is no longer to simply reduce and eliminate waste and by-products but to maximise resource recovery in a safe and sustainable way. It is mandatory to face those challenges that will be reinforced with the growing population and the denser cities that are predicted for the near future. In this context, international researchers involved in waste/ wastewater management question their role in the innovation process and how their activities are influenced by the new paradigm (from waste to resource), and vice-versa. So, how are researchers working to rise to these challenges? How do they imagine waste-to-value or wastewater-to-resource solutions engaging in the circular economy for today and tomorrow? 


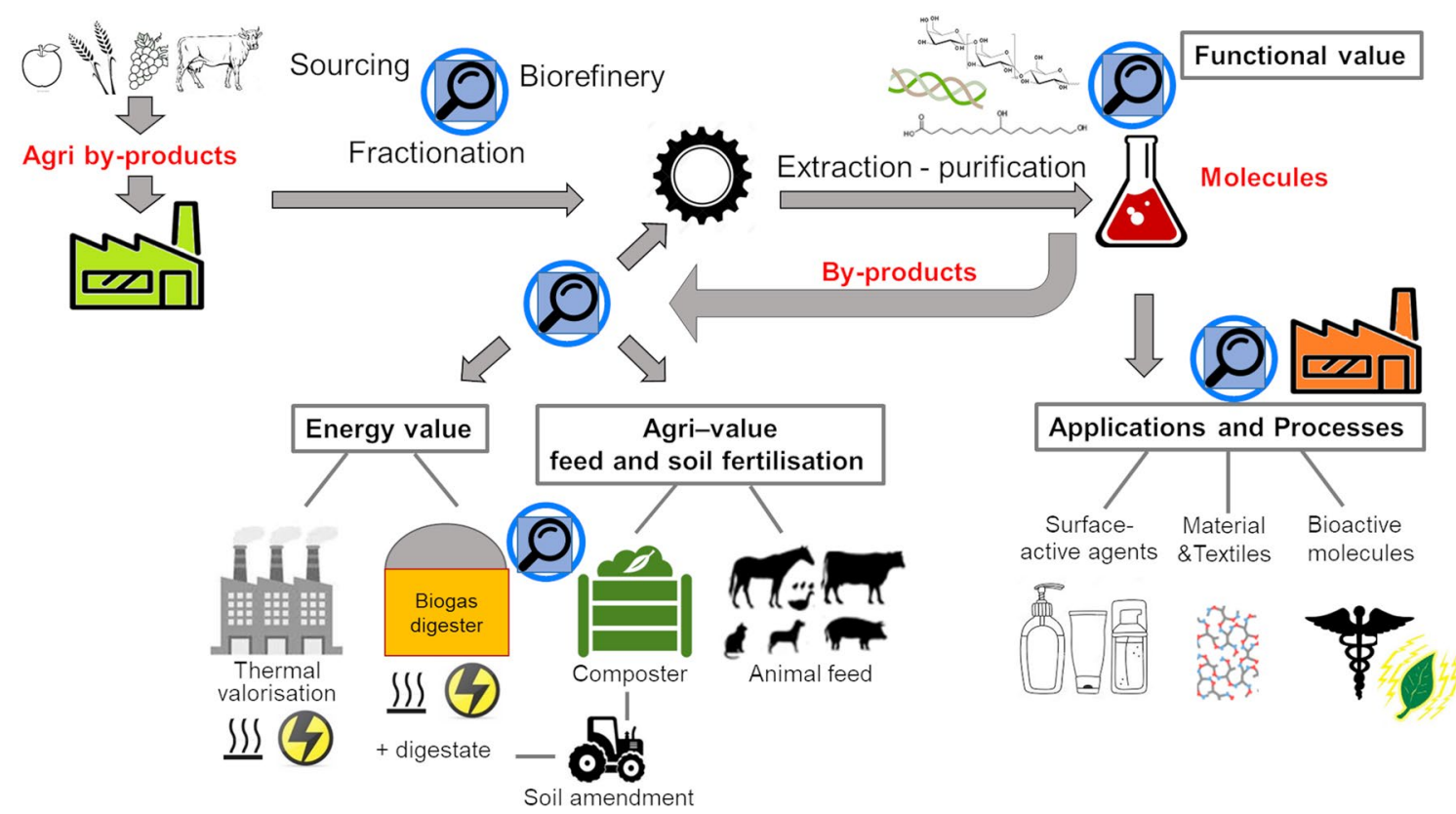

Fig. 1 The role of research scientists in the valorization of agricultural and industrial by-products. Scientists (illustrated by a magnifying glass) enable the processes' design from the fractionation of the agri by-products to the subsequent extraction and purification of high-value molecules. The fields of application are wide like surface cleaning, material and pharmaceutic. Scientists also make it possible to increment processes for a cascade valorization of the by-products.

\section{How Can Research Help Forge a Sustainable Future?}

For research scientists, the task of imagining a sustainable future is far from straightforward, as it requires a thorough and thoughtful evaluation of all plausible scenarios of soon-to-come patterns of socio-economic changes as well as their impacts on production systems at various scales. A system based on circular economy aims not only to give new added value to bio-waste and residual resources, but also to maintain the value of all types of resources for as long as possible, without harming the environment. In particular, bio-based products, bioenergy and wastewater reuse are key sectors in which research and innovation have a key role to play in the near future to develop technological and chain solutions supporting the deployment of circular bioeconomies [12]. To illustrate the challenges and potential impacts related to circular bioeconomy, one can mention Ronzon and Piotrowskiwe [13] who estimated that 395 million tonnes of dry matter $(\mathrm{Tdm})$ of primary agricultural residues was produced in Europe in 2013 from more than 130 crop commodities, of which 69 million Tdm is collectable as feedstock for the biobased material and bioenergy sectors.
To do so, they develop innovative sustainable processes including digester and composter that are integrated in systems providing new opportunity for economic development, e.g. energy and heat, and animal feed and soil amendment. Multi-disciplinary approaches such as biochemistry, chemistry, physico-chemistry, microbiology and process engineering are required to ensure an efficient and complete value-chain

\section{By Proposing Innovative Processes and Integrated Multi-Process Systems}

The trajectory of innovation in biomass, organic residues and wastewater management has so far been driven by sanitary and environmental concerns (generally supported by regulation) and economic development needs (including process efficiency and optimisation of energy consumption). Today's research challenges revolve more around developing innovative integrated systems that mobilise smart new approaches and technologies to readapt our transformation and production systems. Flexibility is needed to cope with market-driven changes in substrates and products, and make the multi-process system as sustainable as possible.

In agri-food industry, such as starch and sugar manufacturing industries, the valorization of side streams was already developed to produce a large panel of products. The "whole crop biorefining" also offers a portfolio of various products from grains and plant side streams such as straws and brans, $[14,15]$. More recently, intensive investigation was put into reengineering the pretreatment processes conventionally applied to improve plant residues deconstruction and facilitate the recovery of high-value, low-concentration specific fractions. However, concerning animal by-products, innovative and non-conventional processes still need to be 
implemented to harness their biological and technical potential. Here, the concept of "innovation" could materialise through a raw-matter resource (the discarded animal tissues) that is largely under valorised worldwide for the recovery of specialty chemicals (just 1-2\% for opotherapy and $1 \%$ for the recovery of gelatine; [16]). Harnessing this innovative resource requires processes that differ from those conventionally used to convert animal by-products into low-value products (mainly pet food) which were mainly designed to minimise the huge amounts generated, estimated to be 20 and 100 million tons worldwide, each year, from fisheries and meat (cattle, pigs and poultry) respectively, where ca. 5.2 and 16.5 million tons, respectively, arise from the sole European Union [16].

The concept of environmental biorefinery was also explored for waste and wastewater treatment $[17,18]$. It involves the incremental integration of mature processes into existing plants to give added value $[9,19,20]$. For example, such an approach could reduce the energy consumption of wastewater treatment plants by a factor of more than 10 and could even make wastewater treatment plants energy positive while they represent today about 5\% of the energy consumption of a developed country [21]. Although the proposed technologies are not necessarily disruptive, their integration into a multi-process system provides new opportunities for economic development. In the future, combining biological and physical-chemical technologies will turn anaerobic digestion and wastewater treatment plants into bioresource factories that goes beyond energy production. This could produce a wide range of valuable end-products, from biofuels and bioenergy (via biogas, biohydrogen and algaculture) to bio-based platform molecules $\left(\mathrm{H}_{2}\right.$, short-chain or medium-chain organic acids) and biopolymers such as alginate-like extracellular polymeric substances $[22,23]$ and even protein sources [19]. Also of interest are the remaining elements, which are recalcitrant to biodegradation. They will be recovered in sludge and digestate that have lower economic value but high value in terms of ecosystem services (e.g., recycling nitrogen and phosphorous but also producing biopesticides, biosurfactants and composite materials for agricultural purposes) [24]. Furthermore, improved valorisation of sludge and digestate can be performed through post-treatment as filtration, evapo-concentration, composting, pyrolysis or co-gasification, etc. [25].

Lastly, introducing sustainability and circularity into process development adds a challenge for researchers since it co-addresses production performance, energy conservation, environmental safety, and the health-hygiene credentials of the end-products. Indeed, an optimised multi-process system differs from the sum of its individually optimised core technologies. For example, some processes used to remove organic micro pollutants (antibiotics, detergents, etc.) or microbial contaminants (pathogens, virus, etc.) are heavily energy-intensive, but alternative processes that are less energy-consuming cannot be developed at the expense of end-product quality. Downstream usages are also crucially important to sustain the use of new technologies. Technological innovations investigating the effect of anaerobic digestion on digestate quality and the fate of nutrients after soil amendment give a case-in-point illustration of the kind of tradeoffs researchers have to handle. Given the high number of parameters to deal with, it has become crucial to develop numerical multi-objective optimisation models to design efficient and sustainable multi-process systems. With this in mind, it is essential to model basic and applied research on each of the core technologies and bring them together into an integrated system to move innovation up towards competitive industry operation.

\section{By Promoting the Emergence of Multi-Scale and Cross-Sectoral Organisations}

For years, specialization, centralization and search for an economy of scale have pushed developers towards high capacity processes. In this context, the challenge to face was often process up scaling. Nowadays, the development of local economies, based on the creation of short food channels or for example on decentralized waste management, drives the adaptation of the process scale to a chain or a territory. However, downscaling of optimised large-scale processes involves critical issues in terms of scale limit and end-products production and valorisation. Beyond the technological aspects, making the chain economically viable is also a challenge. The need for economies of scale and return on investment still favours larger centralised facilities, but different scales of processes can probably coexist within the same territory depending on the resources they use and the services they generate. Looking for example at breweries, there are still a small number of large groups mass-producing big brand beers, but the growing market is for small 'craft' breweries whose economic model is very different. Waste/wastewater management could follow the same trajectory, with a few large centralised plants operating alongside and smaller-sized tailor-made facilities adapted to each territory and dedicated to specific waste-to-value streams with higher added value [20]. Another example of how multi-scale infrastructures can coexist comes from integrated nature-based solutions for wastewater or leachate treatment in urban areas, where they are seen as good candidate solutions to increase urban resilience while contributing to the circular water economy [26, 27].

Actually, organisational factors are source of innovation. A biorefinery or an anaerobic digester system has a radius of action, i.e. the maximum distance from which resources can be recovered, which makes it vital to properly size and localise. For biogas plants, the location of the digester will 
also dictate the valorisation pathway of the biogas, i.e. grid injection, heat and electricity production, or as biofuel. It is also important to consider properly the stability of the organic residues and waste streams to ensure good storage and transport management without degradation and sanitary nuisance that would blunt the extraction yield of target functional molecules.

In this context, why not imagine a future where citizens self-manage their local waste community and profit from it? Such innovative project in circular micro-bioeconomy would require citizens and local stakeholders to become actors in their end-to-end biowaste management chain, from waste collection to process supervision. The drivers for this kind of change in chain pathway are much diverse. They can encompass economics, regulatory pressure, or technology-related constraints, but also reflect a more proactive engagement supported by community consensus, new opportunities or fresh ideologies. Here is a challenge for researchers to meet with companies and many stakeholders to engage in dialogue. In fact, moving outside of his or her core competencies and their comfort zone is a true challenge for everyone. Furthermore, a multisector strategy also hinges on potential complementarities or competition from different economic sectors in the same territory. This makes it important to consider the different by-products generated within a territory, particularly by agro-industry, in order to assess the potential for waste-to-value synergies. The transformation of wastewater treatment plants into recovery facilities of water resource requires a move from a pollution removal scheme to a biorefinery and energy supply scheme.

\section{By Developing Multi-Performance Methods to Evaluate Systems and Organisations}

Efforts to evaluate processes and process chains in a circular bioeconomy run up against several difficulties, partly due to the existing evaluation methodologies and partly due to the lack of data $[28,29]$. The first difficulty arises from the constructs of 'sustainability' and 'circularity' used to define bioeconomy. Sustainability requires that the processes and process chains developed safeguard the environment and support economic activity. It also requires a projection over time of the positive and negative impacts of the process or the sector, sometimes within territorial boundaries. Circularity raises questions about safety and nuisance that are very important issues in the field of wastewater reuse and waste valorisation, especially when there are conflicts over how to use the local resource, as is the case with treated wastewater reuse. Both require new value indicators to be developed and integrated into existing assessment tools such as life cycle assessment and efficient multi-objective optimization [30, 31 ], as proposed in social life cycle assessment for instance.
Other difficulties arise from multi-scale processes and the complexity of the network created by circularity [32]. The evaluation of multi-scale processes means that chain services that were usually evaluated separately now need to be evaluated as a single process route. Moreover, when a circular bioeconomy network interconnects matter, water and energy flows between three or more stakeholders, it may become extremely difficult to decipher and assess the entire network. Finally, if an innovative process is really disruptive with existing technologies or process chains, researchers need to extrapolate laboratory data to industrial processes with evident uncertainties, making it difficult to assess its risks and benefits compared to existing reference routes [33]. Therefore, new evaluation methods and multi-performance indicators are necessary making this topic of research a rapidly expanding area [34] to be further used for risk assessment and policy development.

\section{By Rethinking Research-Society Intersections}

Researchers play a key role in the diffusion of scientific and technological knowledge in society. However, public acceptance and appropriation of new technologies, products or practices is never a foregone conclusion. What are the obstacles to organic residues and wastewater valorisation? There are several aspects to consider. The first concerns the products obtained from residual matter. Even if socioeconomic and legislative landscapes are changing-largely thanks to increasing public awareness of the value of natural resources and the importance of sustainable production ways-consumers are not always receptive to the idea of using products obtained from what is currently considered 'waste'. This is particularly true for products derived from animal residues, organic waste or treated wastewater [35]. How many people today are ready to use cosmetics made from animal by-products or organic waste? How many are ready to drink purified treated wastewater? This is where research can play a transformative role in helping to change consumer conceptions by bringing the data to demonstrate that molecules obtained from today's residues are entirely safe and have unique value.

Public readiness to accept a biotech innovation can be interpreted through the construct of Technology Readiness Index (TRI). TRI is defined as "people's propensity to embrace and use new technologies for accomplishing goals in home life and at work" [36]. For example, the public feedback was estimated for a new technology whose principle is to produce molecules by microbial electrosynthesis that is driven by organic waste oxidation [37]. Analysis identified three main trends of opinion: (i) a group that 'adhered' to the new technology on the basis of rational arguments related to the necessity to valorise waste and to positive perception of biotechnologies (high TRI); (ii) a group that 
rejected the technology on the basis of rational arguments related to potential negative effects of massive waste treatment processes on waste reduction and negative perception of technologies in general (low TRI); (iii) a group of non-specialists that questioned whether it was possible to scale down the technology for a small community or even a household. This third group was generally well informed about waste-to-value and often referred to recent trends in micro-anaerobic digestion (medium TRI). Major transdisciplinary research, including social science, stakes should then be to first enhance the knowledge of these trends of opinion in the field of environmental biotechnologies, and second assess their impact on the general acceptance of innovative technologies and evaluate whether they are impacted by the involvement of technology researchers in the public debate.

Finally, concerning the installation of new waste treatment plants, public opposition is often characterised through the NIMBY ('not in my back yard') concept [38]. Analysis of many case studies on opposition to anaerobic digestion plants in Europe has found that the limiting steps are rather "non-technological" barriers [39-41] that can be collapsed into four categories: economic (investments, grants), administrative (policy and support measures, overwhelming bureaucracy), market-related barriers (new technologies know-how, supply-chain coordination), and public acceptance issues. Public opposition often relies on the trust citizens are ready to invest in policymakers and business, and includes the concepts of equity in the distribution of costs and benefits of the project. Participatory and communitybased research projects have proven to be more successful than projects sponsored by local institutions, agencies or businesses [38, 42-44]. The experiments reported by Zero Waste Europe demonstrate that new strategies for organic waste management with a better involvement of citizens and better communication among stakeholders can contribute to improved recycling rates and boost local employment [45, 46]. In this aim, the Horizon2020 EU R\&I programme subsection 'societal challenges' served to frame the DECISIVE project [47] which proposes an innovative biowaste management scheme based on a network of short circuits for recycling urban biowaste in local urban or peri-urban farming. The concept turns biowaste into a resource to produce energy and bioproducts for local farming and food production (Fig. 2).

All these examples underline the need for stronger involvement of local stakeholders, and particularly citizens, and social sciences in innovation processes. With that vision, the European Commission birthed a programme called SwafS-Science with and for Society to build interplays between science and society at national and international level. Starting from 2015, the programme set out three strategic priorities: Open innovation, Open science, Open to the world (the 'three Os' strategy; [48]). These three Os have revolutionised the whole conception of research, development and innovation and brought a paradigm shift in scientist-policymaker relations. In line with the EU strategy, researchers are increasingly developing projects based on participative science where programmes are co-designed with citizens, stakeholders and end-users. An example was the Companion Modelling approach [49] that created

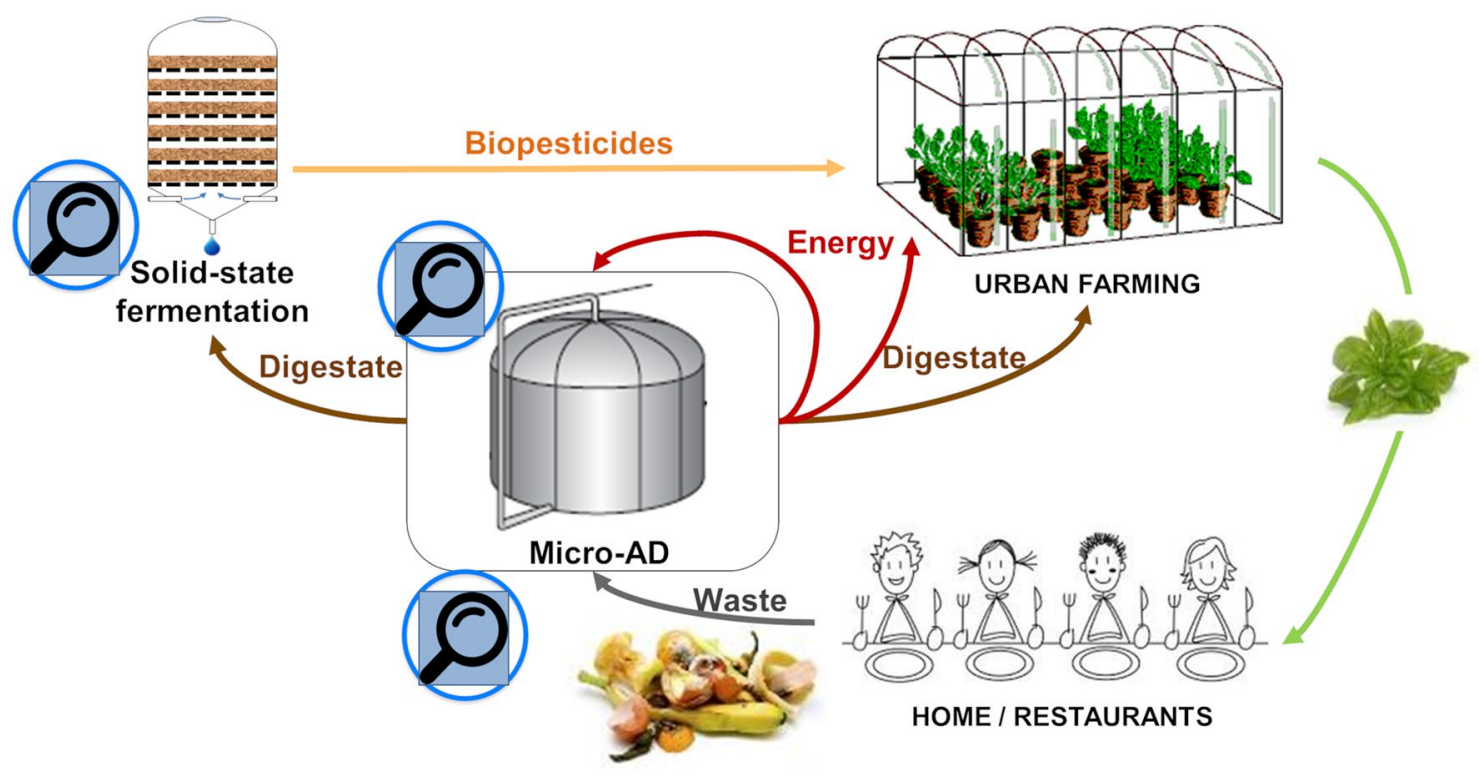

Fig. 2 The DECISIVE biowaste management concept scheme for recycling urban waste in local urban farming. Food from urban farming is locally consumed at home or in restaurants, thus generating wastes being themselves treated in a micro anaerobic digester to produce energy and digestate used in urban farming. So that the cycle is closed. A magnifying glass illustrates scientists 
a role-playing game (WasteWAG, Ter'Aguas) to guide the creation and optimisation of sanitation services adapted to developing countries.

\section{By Enhancing Research-Legislation Interactions}

Innovations brought by scientific developments on residual biomass valorisation may not fit the older established legislative framework; as such, certain bottlenecks in the regulations may warrant review. Even though much progress has been made on the high-value recycling of agri-food residues and wastewater, provisional exemptions to governing regulations could, for instance, open a pathway to novel applications for molecules recovered from that biomass, which in turn could bring about novel organisational systems and new forms of employment. In many countries worldwide, the precautionary principle [50] may be sometimes interpreted as a damper to innovation and then represent a dilemma for decision makers in residual biomass valorisation. Recourse to that principle is generally used when potentially negative effects from a product or process have been clearly identified and/or when the scientific data needed to determine the risk is deficient. Other cases require what the legislative EU communication calls "examination of the benefits and costs of action or lack of action", which should be based on socio-economic considerations. As also established therein, scientific research has a crucial role to play, since the precautionary principle is periodically revised according to the latest developments and data.

It is now widely accepted that scientific advice is hugely important for public policy and decision-making [51], and over the last decade, governance organisations have increased their commitment to informing policy decisions with the best scientific knowledge available. This has in turn generated the creation and expansion of several types of science advisory structures in several countries [52]. A hierarchy of values and aim to reconcile the diverse and sometimes divergent interests and expectations of society's constituent groups and communities should always guide changes in regulations. Population wellbeing, environmental stewardship, and new jobs and growth opportunities through a cleaner and greener production industry (technologies, pharmaceuticals, food, land fertilisation, etc.) can also coexist peacefully with profitable industry thanks to academic scientific research bringing new products/processes to market.

In the European Union, independent scientific policy advice comes through the European Commission's Science Advice Mechanism, which consists of the Group of Chief Scientific Advisors and the Science Advice for Policy by European Academies (SAPEA) consortium composed of academic researchers. The advisors are consulted each time science advice based on public research is critical to developing EU policy and legislation [53]. The recent directive on waste [54] and the brand new regulation on fertilisers [55] are both examples of the latest progress made by scientific research on agriwaste management and valorisation. Directive EU 2018/851 [53] amends the 2008 text by promoting better waste practices to support the transition toward a circular economy and guarantee long-term competitiveness for the European Union. The new regulation on fertilisers amends the 2003 text by including animal by-products as sources of nutrients for soil and soil improvers and considering them as promising raw materials for the production of innovative fertilisers in a circular economy. Regulation EC 1069/2009 [56] on animal by-products has thus been amended, and changes entered into force from 8 April 2020.

To inform these new regulations and support the advisory groups, results from research have to be mobilised beyond the scientific literature. Involving researchers in cross-disciplinary scientific assessment is a key way forward to gather worldwide knowledge on a specific question and bring it to the attention of decision-makers.

\section{Conclusions}

Forging new circular bioeconomy pathways is one of the most exciting challenges for research. It is no easy task, as it requires a firm cohesive understanding of science, society, human behaviour, the environment, and regulatory, industrial and economic landscapes in order to strike the right balance between creativity and practicality as we map out possible scenarios for the future.

All of this has changed the way researchers conduct their studies. Just a few years ago, it was still possible to optimise the productivity or profitability of a process by focusing on one single factor or on a short to medium time horizon. Today, processes cannot be understood as standalone units, and the criteria for optimisation have to include multiple dimensions and to be analyzed on a long term. The main consequences are that: (i) processes for circular economy have to be engineered for modularity (due to multiple and scarce sourcing channels, variable quantity-quality of the resources, and other constraints), for resilience (due to unexpected events such as shortages in available raw feedstocks) and must combine strong public health and safety credentials; (ii) mathematical tools and multi-criteria optimisation have to be accounted for and embedded in experimental studies to evaluate the relevance of their objectives in terms of their economic, environmental and social dimensions; (iii) public acceptance has to be factored in from the beginning and not, as was often done in the past, after the innovation has been optimised; (iv) legislation has to be reassessed regularly to adapt to new scientific knowledge and technical developments. In addition, in terms of bio-sourced products, 
it is important to move forward from producing addedvalue biomolecules to replace oil-sourced molecules to a bio-functionality paradigm-in other words, it is not the molecule itself that has to be replaced but the service that it brings.

One last important aspect shaping today's studies is the time and geographic scales in which they have to be conducted to avoid inconclusive experiments. To drive change, public and private researchers need the freedom to experiment new technological and organisational systems at relevant spatial (i.e. large) and temporal (i.e. long) scales. This will require longer-term public funding, i.e. some grants running longer than the current 3 to 4 -year model, and possibly also at least a temporary readjustment of the current rules and regulations over test territories. With that vision, research will also certainly need to capture public support and consent and committed political backing, which is another challenge in itself.

Acknowledgements The authors thank Pascale Manchado-Sarni for her upstream work on food waste and her advice to write this article.

Author Contributions Conceptualization: All authors, Formal analysis and investigation: All authors except RB, Writing —original draft preparation: All authors; Writing — review and editing: All authors, Supervision: RB.

Funding This research did not receive any specific grant from funding agencies in the public, commercial, or not-for-profit sectors for the submitted work.

\section{Declarations}

Conflict of interest The authors declare that they have no known competing financial interests or personal relationships that could have appeared to influence the work reported in this paper.

Open Access This article is licensed under a Creative Commons Attribution 4.0 International License, which permits use, sharing, adaptation, distribution and reproduction in any medium or format, as long as you give appropriate credit to the original author(s) and the source, provide a link to the Creative Commons licence, and indicate if changes were made. The images or other third party material in this article are included in the article's Creative Commons licence, unless indicated otherwise in a credit line to the material. If material is not included in the article's Creative Commons licence and your intended use is not permitted by statutory regulation or exceeds the permitted use, you will need to obtain permission directly from the copyright holder. To view a copy of this licence, visit http://creativecommons.org/licenses/by/4.0/.

\section{References}

1. Calvo, G., Valero, A., Valero, A.: Assessing maximum production peak and resource availability of non-fuel mineral resources: analyzing the influence of extractable global resources. Resour. Conserv. Recycl. 125, 208-217 (2017). https://doi.org/10.1016/j.resconrec.2017.06.009

2. Elser, J.J.: Phosphorus: a limiting nutrient for humanity? Curr. Opin. Biotechnol. 23, 833-838 (2012). https://doi.org/10. 1016/j.copbio.2012.03.001

3. Martins, F., Felgueiras, C., Smitkova, M., Caetano, N.: Analysis of fossil fuel energy consumption and environmental impacts in European countries. Energies 12, 964 (2019). https://doi.org/10. 3390/en12060964

4. Gustavsson, J., Cederberg, C., Sonesson, U., van Otterdijk, R., Meybeck, A.: Global food losses and food waste. Extent, causes and prevention. FAO, Rome (2011)

5. Fisgativa, H., Tremier, A., Dabert, P.: Characterizing the variability of food waste quality: a need for efficient valorisation through anaerobic digestion. Waste Manag. 50, 264-274 (2016). https://doi.org/10.1016/j.wasman.2016.01.041

6. The World Bank: What a waste 2.0: global snapshot of solid waste management to 2050. https://datatopics.worldbank.org/what-awaste/ (2018). Accessed 12 Jan 2021

7. Kaza, S., Yao, L., Bhada-Tata, P., van Woerden, F.: What a waste 2.0: a global snapshot of solid waste management to 2050. The World Bank, Washington (2018)

8. Cerda, A., Artola, A., Barrena, R., Font, X., Gea, T., Sánchez, A.: Innovative production of bioproducts from organic waste through solid-state fermentation. Front. Sustain. Food Syst. (2019). https:// doi.org/10.3389/fsufs.2019.00063

9. Mullen, A.M., Álvarez, C., Zeugolis, D.I., Henchion, M., O'Neill, E., Drummond, L.: Alternative uses for co-products: harnessing the potential of valuable compounds from meat processing chains. Meat Sci. 132, 90-98 (2017). https://doi.org/10.1016/j.meatsci. 2017.04.243

10. Skaggs, R.L., Coleman, A.M., Seiple, T.E., Milbrandt, A.R.: Waste-to-energy biofuel production potential for selected feedstocks in the conterminous United States. Renew. Sustain. Energy Rev. 82, 2640-2651 (2018). https://doi.org/10.1016/j.rser.2017. 09.107

11. United Nations: The sustainable development goals report. United Nations Publications, New York (2020)

12. Neczaj, E., Grosser, A.: Circular economy in wastewater treatment plant-challenges and barriers. Proceedings 2, 614 (2018). https:// doi.org/10.3390/proceedings2110614

13. Ronzon, T., Piotrowski, S.: Are primary agricultural residues promising feedstock for the European bioeconomy? Ind. Biotechnol. 13, 113-127 (2017). https://doi.org/10.1089/ind.2017.29078. tro

14. de Jong, E., Jungmeier, G.: Biorefinery concepts in comparison to petrochemical refineries. In: Industrial biorefineries and white biotechnology, pp. 3-33. Elsevier, Amsterdam (2015)

15. De Corato, U., De Bari, I., Viola, E., Pugliese, M.: Assessing the main opportunities of integrated biorefining from agro-bioenergy co/by-products and agroindustrial residues into high-value added products associated to some emerging markets: a review. Renew. Sustain. Energy Rev. 88, 326-346 (2018). https://doi.org/10. 1016/j.rser.2018.02.041

16. Ferraro, V., Anton, M., Santé-Lhoutellier, V.: The "sisters" $\alpha$-helices of collagen, elastin and keratin recovered from animal by-products: functionality, bioactivity and trends of application. Trends Food Sci. Technol. 51, 65-75 (2016). https://doi.org/10. 1016/j.tifs.2016.03.006

17. Leong, H.Y., Chang, C.-K., Khoo, K.S., Chew, K.W., Chia, S.R., Lim, J.W., Chang, J.-S., Show, P.L.: Waste biorefinery towards a sustainable circular bioeconomy: a solution to global issues. Biotechnol. Biofuels 14, 87 (2021). https://doi.org/10.1186/ s13068-021-01939-5

18. Guerra-Rodríguez, S., Oulego, P., Rodríguez, E., Singh, D.N., Rodríguez-Chueca, J.: Towards the implementation of circular 
economy in the wastewater sector: challenges and opportunities. Water 12, 1431 (2020). https://doi.org/10.3390/w12051431

19. Puyol, D., Batstone, D.J., Hülsen, T., Astals, S., Peces, M., Krömer, J.O.: Resource recovery from wastewater by biological technologies: opportunities, challenges, and prospects. Front. Microbiol. 7, 23p (2017). https://doi.org/10.3389/fmicb.2016. 02106

20. Vea, E.B., Romeo, D., Thomsen, M.: Biowaste valorisation in a future circular bioeconomy. Procedia CIRP 69, 591-596 (2018). https://doi.org/10.1016/j.procir.2017.11.062

21. Batstone, D.J., Hülsen, T., Mehta, C.M., Keller, J.: Platforms for energy and nutrient recovery from domestic wastewater: a review. Chemosphere 140, 2-11 (2015). https://doi.org/10.1016/j.chemo sphere.2014.10.021

22. Felz, S., Al-Zuhairy, S., Aarstad, O.A., van Loosdrecht, M.C.M., Lin, Y.M.: Extraction of structural extracellular polymeric substances from aerobic granular sludge. J. Vis. Exp. (2016). https://doi.org/10.3791/54534

23. Pronk, M., Giesen, A., Thompson, A., Robertson, S., van Loosdrecht, M.: Aerobic granular biomass technology: advancements in design, applications and further developments. Water Pract. Technol. 12, 987-996 (2017). https://doi.org/10.2166/wpt.2017. 101

24. Moscoviz, R., Trably, E., Bernet, N., Carrere, H.: The environmental biorefinery: state-of-the-art on the production of hydrogen and value-added biomolecules in mixed-culture fermentation. Green Chem. 20, 3159-3179 (2018). https://doi.org/10. 1039/c8gc00572a

25. Guilayn, F., Rouez, M., Crest, M., Patereau, D., Jimenez, J.: Valorization of digestates from urban or centralized biogas plants: a critical review. Rev. Environ. Sci. Biotechnol. 19, 419-462 (2020). https://doi.org/10.1007/s11157-020-09531-3

26. The United Nations: Nature-based solutions for water. United Nations Educational, Scientific and Cultural Organization (UNESCO), Paris (2018)

27. Kopsieker, L., Gerritsen, E., Stainforth, T., Lucic, A., Costa Domingo, G., Naumann, S., Röschel, L., Davis, M.: Naturebased solutions and their socio-economic benefits for Europe's recovery: enhancing the uptake of nature-based solutions across EU policies. IEEP, London (2021)

28. Aissani, L., Lacassagne, A., Bahers, J.-B., Féon, S.L.: Life cycle assessment of industrial symbiosis: a critical review of relevant reference scenarios. J. Ind. Ecol. 23, 972-985 (2019). https:// doi.org/10.1111/jiec. 12842

29. Bellon-Maurel, V., Aissani, L., Bessou, C., Lardon, L., Loiseau, E., Risch, E., Roux, P., Junqua, G.: What scientific issues in life cycle assessment applied to waste and biomass valorization? Waste Biomass Valoriz. 4, 377-383 (2013). https://doi.org/10. 1007/s12649-012-9189-4

30. Loiseau, E., Aissani, L., Le Féon, S., Laurent, F., Cerceau, J., Sala, S., Roux, P.: Territorial life cycle assessment (LCA): what exactly is it about? A proposal towards using a common terminology and a research agenda. J. Clean. Prod. 176, 474-485 (2018). https://doi.org/10.1016/j.jclepro.2017.12.169

31. de Faria, A.B.B., Ahmadi, A., Tiruta-Barna, L., Spérandio, M.: Feasibility of rigorous multi-objective optimization of wastewater management and treatment plants. Chem. Eng. Res. Des. 115, 394-406 (2016). https://doi.org/10.1016/j.cherd.2016.09. 005

32. Teigiserova, D.A., Hamelin, L., Thomsen, M.: Towards transparent valorization of food surplus, waste and loss: clarifying definitions, food waste hierarchy, and role in the circular economy. Sci. Total Environ. 706, 136033 (2020). https://doi.org/10. 1016/j.scitotenv.2019.136033

33. Foulet, A., Bouchez, T., Desmond-Le Quéméner, E., Giard, L., Renvoisé, L., Aissani, L.: Eco-design of microbial electrochemical technologies for the production of waste-based succinic acid thanks to a life cycle assessment. J. Clean. Prod. 225, 1155-1168 (2019). https://doi.org/10.1016/j.jclepro.2019. 03.231

34. Vea, E.B., Martinez-Sanchez, V., Thomsen, M.: A review of waste management decision support tools and their ability to assess circular biowaste management systems. Sustainability 10, 3720 (2018). https://doi.org/10.3390/su10103720

35. Fielding, K.S., Dolnicar, S., Schultz, T.: Public acceptance of recycled water. Int. J. Water Resour. Dev. 35, 551-586 (2019). https://doi.org/10.1080/07900627.2017.1419125

36. Parasuraman, A.: Technology readiness index (TRI): a multipleitem scale to measure readiness to embrace new technologies. J. Serv. Res. 2, 307-320 (2000). https://doi.org/10.1177/10946 7050024001

37. Biorare project. https://biorare.inrae.fr/ (2017). Accessed 21 April 2021

38. Soland, M., Steimer, N., Walter, G.: Local acceptance of existing biogas plants in Switzerland. Energy Policy 61, 802-810 (2013). https://doi.org/10.1016/j.enpol.2013.06.111

39. Capodaglio, A.G., Callegari, A., Lopez, M.V.: European framework for the diffusion of biogas uses: emerging technologies, acceptance, incentive strategies, and institutional-regulatory support. Sustainability 8, 298 (2016). https://doi.org/10.3390/ su8040298

40. McCormick, K., Kåberger, T.: Key barriers for bioenergy in Europe: economic conditions, know-how and institutional capacity, and supply chain co-ordination. Biomass Bioenergy 31, 443-452 (2007). https://doi.org/10.1016/j.biombioe.2007. 01.008

41. Pitkänen, K., Antikainen, R., Droste, N., Loiseau, E., Saikku, L., Aissani, L., Hansjürgens, B., Kuikman, P.J., Leskinen, P., Thomsen, M.: What can be learned from practical cases of green economy? Studies from five European countries. J. Clean. Prod. 139, 666-676 (2016). https://doi.org/10.1016/j.jclepro.2016.08. 071

42. Magnani, N.: Exploring the local sustainability of a green economy in alpine communities. Mt. Res. Dev. 32, 109-116 (2012). https://doi.org/10.1659/MRD-JOURNAL-D-11-00105.1

43. Rogers, J.C., Simmons, E.A., Convery, I., Weatherall, A.: Public perceptions of opportunities for community-based renewable energy projects. Energy Policy 36, 4217-4226 (2008). https:// doi.org/10.1016/j.enpol.2008.07.028

44. Walker, G., Devine-Wright, P., Hunter, S., High, H., Evans, B.: Trust and community: exploring the meanings, contexts and dynamics of community renewable energy. Energy Policy 38, 2655-2663 (2010). https://doi.org/10.1016/j.enpol.2009.05.055

45. Van Vliet, A.: Case study 1: the story of Capannori. Zero Waste Europe, Leiden (2014)

46. Van Vliet, A.: Case study 2: the story of Argentona. Zero Waste Europe, Leiden (2014)

47. DECISIVE 2020-A decentralised management scheme for innovative valorisation of urban biowaste. http://www.decis ive2020.eu/ (2017). Accessed 21 April 2021

48. European Commission: Horizon 2020. Work Programme 20182020. 16. Science with and for Society. European Commission Decision C(2019) 4575. European Commission (2019)

49. ComMod, C.: ComMod: The companion modelling approach. https://www.commod.org/en/ (2005). Accessed 21 April 2021

50. Commision, E.: Communication from the commission on the precautionary principle. Publications Office of the European Union, Brussels (2000)

51. OECD: Scientific advice for policy making: the role and responsibility of expert bodies and individual scientists. OECD Publ., Paris (2015) 
52. Kenny, C., Washbourne, C.-L., Tyler, C., Blackstock, J.J.: Legislative science advice in Europe: the case for international comparative research. Palgrave Commun. 3, 1-9 (2017). https://doi. org/10.1057/palcomms.2017.30

53. SAM, Scientific Advice Mechanism: From questions to answers. How the European Commission's scientific advice mechanism produce scientific advice to support policy making. European Commission, Brussels, 14 March 2019 (2019). https://ec. europa.eu/info/files/guidelines-how-sam-produces-scientificadvice_en. Accessed 14 Jan 2020

54. European Commission: Directive (EU) 2018/851 of the European Parliament and of the council of 30 May 2018 amending directive 2008/98/EC on waste. European Union (2018). https:// eur-lex.europa.eu/legal-content/EN/TXT/HTML/?uri=CELEX: 32018L0851\&from=EN. Accessed 08 April 2020

55. European Commission: Regulation (EU) 2019/1009 of the European parliament and of the council of 5 June 2019 laying down rules on the making available on the market of EU fertilizing products and amending regulations (EC) No 1069/2009 and (EC) No 1107/2009 and repealing regulation (EC) No 2003/2003. Official Journal of the European Union (2019)

56. European Commission: Regulation (EC) No 1069/2009 laying down health rules as regards animal by-products and derived products not intended for human consumption and repealing regulation (EC) No 1774/2002 (animal by-products regulation). Official Journal of the European Union (2009). Report No 1069/2009 L 300/1

Publisher's Note Springer Nature remains neutral with regard to jurisdictional claims in published maps and institutional affiliations.

\section{Authors and Affiliations}

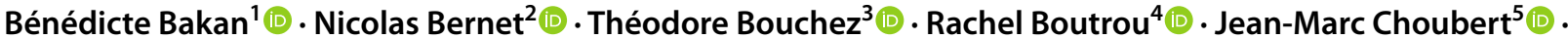

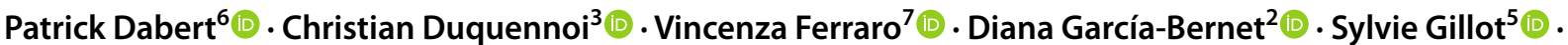

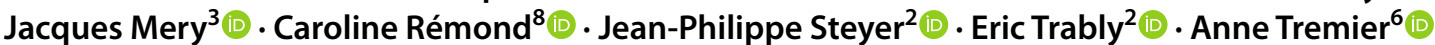

\author{
Rachel Boutrou \\ rachel.boutrou@inrae.fr \\ Bénédicte Bakan \\ benedicte.bakan@inrae.fr \\ Nicolas Bernet \\ nicolas.bernet@inrae.fr \\ Théodore Bouchez \\ theodore.bouchez@inrae.fr \\ Jean-Marc Choubert \\ jean-marc.choubert@inrae.fr \\ Patrick Dabert \\ patrick.dabert@inrae.fr \\ Christian Duquennoi \\ christian.duquennoi@inrae.fr \\ Vincenza Ferraro \\ vincenza.ferraro@inrae.fr \\ Diana García-Bernet \\ diana.garcia-bernet@inrae.fr \\ Sylvie Gillot \\ sylvie.gillot@inrae.fr \\ Jacques Mery \\ jacques.mery@inrae.fr
}

Caroline Rémond

caroline.remond-zilliox@inrae.fr

Jean-Philippe Steyer

jean-philippe.steyer@inrae.fr

Eric Trably

eric.trably@inrae.fr

Anne Tremier

anne.tremier@inrae.fr

1 BIA, INRAE, 44300 Nantes, France

2 LBE, INRAE, Univ Montpellier, 11100 Narbonne, France

3 PROSE, INRAE, Université Paris-Saclay, 92160 Antony, France

4 STLO, INRAE, Institut Agro, 35042 Rennes, France

5 REVERSAAL, INRAE, 69625 Villeurbanne, France

6 OPAALE, INRAE, 35044 Rennes, France

7 QuaPA, INRAE, 63122 Saint-Genès-Champanelle, France

8 FARE, UMR A 614, Chaire AFERE, Université de Reims Champagne-Ardenne, INRAE, 51097 Reims, France 